\title{
SCIENCE OF PROBLEM SOLVING IN A HISTORICAL CONTEXT
}

\author{
Author(s) / Auteur(s) : \\ Janos KORN \\ Doctor, Design Engineer \\ Middlesex University, Department of Design Engineering and Mathematics \\ janos999@btinternet.com
}

\begin{abstract}
Résumé :
The generality of the 'systemic or structural view' of parts of the world is introduced. This leads to the generality of the 'innate' problem solving activity of problematic issues in the living sphere associated with survival or homeostasis, achievements of ambitions by chance or purpose and maintenance of isothermal operations. The anomaly of using predominantly qualitative, quantitative properties over the history of human intellectual endeavour for the development of empirical theories in preference of 'systemic properties', had they been available, is asserted. One-and two-place, declarative sentences of processed natural language acting as such properties, are suggested. Consideration of the notions of achievement and ambition leads to a 'problem solving structure' as the integral part of the 'New science of systems' called the 'Science of problem solving' or the 'Science of the $21^{\text {st }}$ century'. Accordingly, the problematic issues can be resolved and the anomaly to disappear. Aristotle's four causes from the historical background of thought are compared with the problem-solving structure and the problem-solving function and place of conventional science of physics at the object level is discussed leading to a 'scientific enterprise'. Integration of ancient and modern views has emerged. An example of application of 'linguistic modelling' to the problem-solving structure, is given.
\end{abstract}

Keywords / Mots-clés :

problem solving, systems science, linguistic modelling

\section{INTRODUCTION}

We begin by introducing general, empirical concepts as a basis for generating models of scenarios including human activities expressible in operational terms.

Observation of parts of the world tells us that there are objects and agents or 'parts of the world' in relationships recognised as wholes and seen as systems or structures in static (A) or in dynamic (B, C) state, the systemic view [Korn, 2018]. Here they are classified into:

1. Inanimate [A. rock, B. hurricane];

2. Animate [A. products like a bird's nest, B. plants, animals, man at the biological level and C. man at the social level];

3. Artificial [A. products or artifacts like a hammer or a book [Simon, 1996], B. control and computer systems, manufacturing systems].

Any object consisting of a number of repeated constituents forming a structure like a 'salt crystal' or a 'pebble' is designated as a 'simple system'. Objects consisting of a number of constituents performing different functions like a 'bed', a 'cell' or a 'control system' or a 'religious community' are called 'complex systems'.

Animate and artificial, dynamic systems when operate in states B. and C. do so because of the complex networks of processes forming a whole that go on within. These processes have the characteristics:

I. At levels B. and C. animate processes go on at molecular as well as macroscopic levels in order to ensure survival or homeostasis as individuals or groups;

II. At level C. animate processes operate so as to achieve ambitions towards convenience, power, high performance, new constructions of artefacts, machines, buildings, works of arts, 
intellectual works and manufacturing entities and so on at individual and group levels which drive, or vice versa, inventions of artifacts and developments of novel ideas;

III. At levels B. and C. all processes produce irreversibility due to losses and imperfections resulting in generation of material waste and heat or entropy production [Prigogine, 1955, Korn, 2012, 1981].

The characteristics present animate and artificial dynamic systems with the problematic issues of 'how to survive, how to achieve ambitions and how to operate at constant temperature higher than that of their environment so that heat transfer can take place'. These 'issues' call for 'resolution', the alternative is extinction.

Perception and statement of a 'problematic issue' and its attempted 'resolution' is called 'problem solving'. At the molecular as well as at macroscopic levels, 'problem solving' is carried out by systems in 'purposive configuration' [Brown, Campbell, 1948, Monod, 1970, Nise, 2008, Korn, 2012, 2018]. Plants, animals and human beings convert environmental resources into their own use according to plan to facilitate 'survival'. In addition, human beings accomplish this kind of conversion to pursue 'ambitions'. This point could suggest a dividing line between the capabilities of plant/animal and human brain/mind if criterion between activities directed at 'survival' or 'ambitions' could be formulated. The task of the human brain/mind over the ages of its existence has been to generate the 'intellectual processes' to create views or models for understanding aspects of 'problem solving'.

We conclude:

- First $=$ Wiener's description of 'purposive system': 'Cybernetics or control and communication in the animals and machines' is justified but restrictive [Wiener, 1948].

- $\quad$ Second $=$ The exercise of 'problem solving' in the living sphere is innate, universal and is operated instinctively. For this reason, life is so 'resilient'. 'Problem solving' in the living sphere is as common as the action of gravity is in the material sphere. It is an every day occurrence at all levels of existence.

- $\quad$ Third $=$ The 'problem solving process' which has the structure of a 'purposive system' is a particular case of the pervasive, hierarchical, empirical and indivisible 'systemic or structural nature and subsequent view' of parts of the world [Korn, 2018].

The objective of this paper is:

1. To outline a few of the intellectual processes which had been directed at discussing Aristotle's four causes separately or together as a view to understand problems such as the justification for the existence of God and which foresaw the question of 'problem solving'. Here we have an attempt at unifying ancient and modern views.

2. To discuss briefly the limitations of conventional science of physics in handling problems associated with single objects, distributed or point like [Korn, 2018].

3. To describe the inability of current attempts to create views or models to cope with the generality of 'systems thinking' and to handle the 'problematic issues' mentioned above.

4. To introduce a proposed 'New science of systems', the $21^{\text {st }}$ century science, based on the empirical view of the 'systemic or structural phenomenon' as an attempt to resolve these issues.

The lack of a general, intellectual framework for appreciation of the empirical nature and generality of the 'systemic or structural view of parts of the world' has caused problems in teaching, engineering and society and has created a separation from conventional science [Lewin, 1981, Anon., 1983]. The 'New science' aims to unify this historical cleavage. 


\section{A BRIEF HISTORY OF INTELLECTUAL PROCESSES}

Figure 1. shows a summary of intellectual processes reproduced with slight modifications from [Korn, 2020a]. It includes the paradigm changes over history as needed for the present considerations [Kuhn, 1996]. The origin of all developments resides in the invention of the 'subject - predicate form' best expressed by natural language, called the 'primary model' because it is potentially accessible by all [Bevan, 1984]. The diagram branches into 'qualitative, quantitative interest' in terms of which the great majority of intellectual endeavours have taken place. This can be attributed to people's primary interest being in qualitative or quantitative properties of things shown in Table 1.

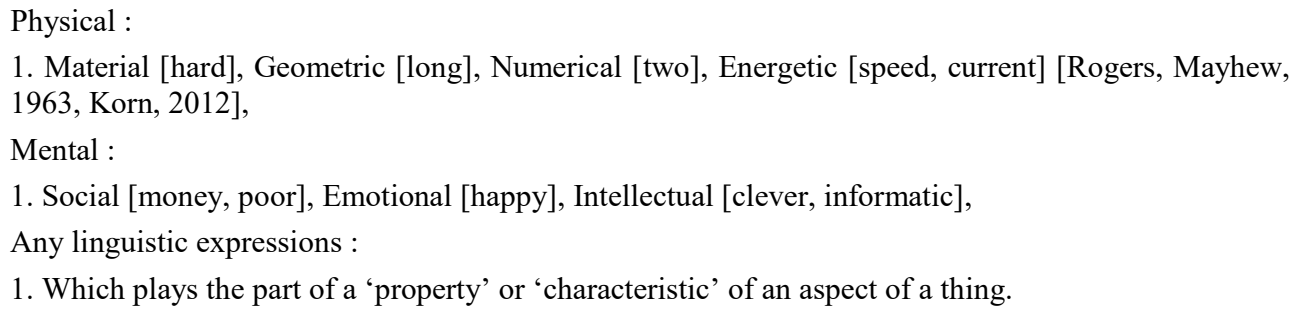

Table 1. Summary of properties

Here is an anomaly between the view in the INTRODUCTION saying that any part of the world is seen as a 'system or structure' yet developments using 'systemic or structural

properties' in Figure 1. are sparse and have taken place relatively recently. An objective of current developments is to suggest the 3rd paradigm change shown in Figure 1. to remedy inadequacies and fragmentation in 'systems thinking' and to introduce the notion of 'problem solving' as the fundamental theme permeating all parts of the world [Korn, 2018, 2020a,b,c].

Perhaps it was Plato (427-347) who introduced a fundamental feature of natural language which enables it to be an efficient means of representation and communication. Plato's eternal 'Forms' are seen as concepts abstracted from particular properties of things which are imperfect and changing and a designation assigned to them. For example, the sensual experience such as 'smooth, white skin, wellproportioned face, rich brown hair' is processed by the brain/mind into the notion of 'beauty'.

This development had been followed in time by Aristotle's four causes (384-322) who believed that they are required for a complete description of a thing. Aristotle's second or 'formal' cause used by Thomas Aquinas (1225-1274) to put forward the teleological argument or design which asserts that certain features of the universe must be the product of an intelligent cause. Francis Bacon (156111626) argued for the development of empirical, inductive approach to study nature and proposed that Aristotle's four causes should be divided into two parts: Physics to deal with the 'material' and 'efficient' causes and the 'formal' and 'final' causes to belong to Metaphysics.

We can place the $1^{\text {st }}$ paradigm change in Figure 1. around this time in the development of conventional science of physics. This epoch up to the present day has seen the immense development and influence of conventional science on technology and as such on society. Recently the view of conventional science as a 'problem solving' exercise has been put forward and the 'demarcation problem' i.e. how to distinguish 'scientific' from other statements, has been solved by introducing the notion of 'falsification' [Popper, 1972, Kuhn, 1996]. A call for regarding the 'systemic view' as the 'third culture' has been proposed [Lewin, 1981].

The answer to this call may be seen a field of study of 'systems thinking' whose job is supposed to be to translate the 'systemic or structural view' into symbolic or theoretical structures or models.

Systems thinking seems to have originated from Maxwell's paper 'On governors' [Maxwell, 1868]. Theoretical approaches on a large scale were developed before, during and after the $2^{\text {nd }} \mathrm{WW}$ and continue to the present time [Blackett, 1948, Brown, Campbell, 1948, Bertalanffy, 1950, Boulding, 1956, Jackson, 2000]. However, they do not satisfy the criteria of being 'scientific', they are inadequate as symbolic description of the 'systemic or structural view' in its generality and 
complexity, mostly speculative, fragmented but inspiring and pioneering. This description is seen as a 'problematic issue' and the 'New Science of Systems', the subject of current development, is an attempt at 'resolution' of this issue. This 'Science' is available to peer scrutiny and, if found acceptable, to applications in teaching and in aiding social, manufacturing and communication functions [Korn, 2009, 2012, 2018, 2019].

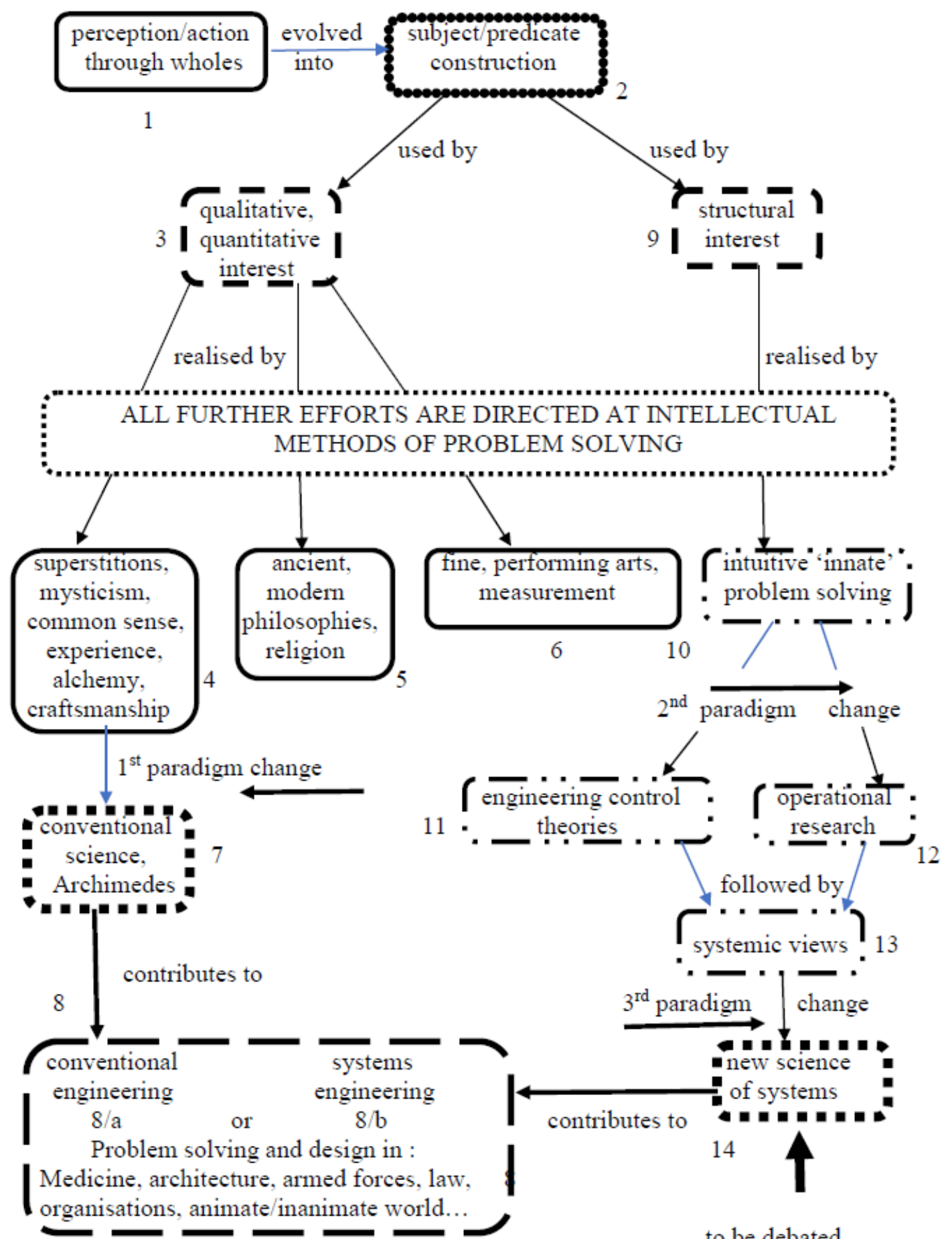

Figure 1. Diagram of constituents of human intellectual endeavour 


\section{AN OUTLINE OF THE PROBLEM-SOLVING SCHEME}

The proposed 'New Science of Systems' is an attempt which satisfies the criteria of being 'scientific' and has been put forward as a possible resolution of the 'problematic issue' [Korn, 2009, 2018, 2020a,b]. Also, the 'new science' shows how to incorporate conventional science with its mathematical models, together with 'problem solving' and design into the framework of a 'scientific enterprise', can handle qualitative, quantitative, social, emotive aspects of parts of the world, highly teachable and is rooted in accepted branches of knowledge and can produce models at operational level.

The 'New Science of Systems' follows the methodology of 'conventional science but with systemic content' : It suggests three basic hypotheses expressed as statements and uses the single method of 'linguistic modelling' as the means of exposing the former to the possibility of refutation [Popper, 1972].

The hypotheses are :

I. About existence of structures : The 'systemic or structural' view of parts of the world is pervasive, indivisible, hierarchical [nested] and empirical. There is no alternative [Korn, 2018].

II. About operation of structures : The purpose of change is 'problem solving' i.e. changes of state from one equilibrium state to another are accomplished by the 'producer - product' dichotomy either by 'chance' or 'in accordance with a purpose' [Korn, 2016].

III. About representation or models : We can make an infinite number of hypothetical statements as declarative sentences about any part of the world or empirical object. Thus, complete knowledge is impossible to attain. In practice, we make one or more consistent statements selected by interest or a point of view of an observer or analysist. Statements can be expressed into a structure of symbols which may be seen as static or dynamic representation of a part of the world or a 'model' [Korn, 2019].

The $1^{\text {st }}$ hypothesis tells us that the 'systemic or structural view' of parts of the world refers to a universal, empirical phenomenon.

The $2^{\text {nd }}$ hypothesis asserts that a state of a part of the world which is in one equilibrium is regarded as a 'problematic issue' and is driven to an other equilibrium state. Changes from one equilibrium state to another is expressed by the 'variational principle' and is formulated explicitly by generalised Kirchoff's laws when possible [Korn, 1981, 2012].

The $3^{\text {rd }}$ hypothesis asserts that living things need a medium for description and communication of their 'thoughts' with its inherent uncertainties due to interpretation.

\section{ACHIEVEMENTS OF LIVING THINGS AND PROBLEM SOLVING}

This part has been reproduced with minor modifications from [Korn, 2020b]. There are two ways a symbolism or a model for description and communication of chosen aspects of a part of the world or empirical object following a 'thought', can be originated as described in the INTRODUCTION. The constituent parts of the 'subject - predicate' form, the carrier of 'complete thoughts', can be qualified by [Burton, 1984] :

QUALITATIVE/QUANTITATIVE properties --- Source of models of objects

These parts are the,

A. Subject : Stands for qualified designation of a concrete, abstract, symbolic, imaginary [centaur] or emotive object for locating the interest of the 'producer of thought' in a part of the world, and

B. Predicate : The qualified designations or 'cases' and the verbs which connect A. and B.

For example : 'The [clever] John is [smart]', 'The car has a [speed of $35 \mathrm{~km} / \mathrm{h}$ ]', 'The [hungry] John went [out to eat] to a [cheap] restaurant'. 
The qualitative/quantitative properties [adjectives and adverbs] make the sentence elements thus the sentence itself, specific or turn a 'context - free' sentence into 'context - dependent' which can be tested against experience [Popper, 1972].

Alternatively, the 'subject - predicate' form can be constructed leading to

RELATIONAL or STRUCTURAL properties --- Source of models of scenarios which consist of

A. Subject : Designates a concrete, abstract, symbolic, imaginary or emotive object, and

B. Predicate : Uses a 'stative' or 'dynamic' verb to indicate static or dynamic state of the 'subject' and the rest of the predicate of the sentence or the description of a scenario.

For example : 'John [floats] on the water (static state)', 'John [jumps] into the [ice cold] water (dynamic state)'. This kind of sentences are the smallest linguistic entities which make 'complete sense' [Burton, 1984]. They are 'ordered pairs' [Korn, 2009].

Descriptions A. and B. together comprise the 'systemic or structural properties' which express the 'relationship' between the 'subject' of a sentence and the predicate created by the 'verb'.

Thinking in terms of relational properties of an object or a scenario is called SYSTEMS THINKING.

Practically the WHOLE of human intellectual and material achievements have been expressed using 'qualitative/quantitative' properties. A reason for this may be due to :

AMBITIONS or objectives of living things like : Survival, convenience, power, influence, improvements in physical and mental well being [own and of others], feelings, emotions, desires, wishes etc. are accessible in the first place by means of the 'senses' and instruments through qualitative/quantitative properties. These are then interpreted by the brain/mind and can be formulated in terms of a suitable symbolism such as writing, mathematics, painting. Any ambition is realised by means of achievement.

For example, Ambition

To survive

To have convenience

To have power

\section{Process of achievement}

Seeking to have food, drink and shelter

Ensuring to use transport instead of walking

Conspiring to depose the government

To have mental well being Going to a museum to look at paintings

where the words in italic designate the achievement and the present participle of dynamic verbs indicate action to produce it. 
Consideration of the notion of ACHIEVEMENT in its widest sense can lead to:

I. The concept of achievement is identified with the notion of product as artefact. Both concepts have a common meaning as 'that brought about by an agent', achievement is usually that by self, product is that by a third party,

II. As says in the $2^{\text {nd }}$ hypothesis, the function of the 'product' is to change the state of an object [the term includes processes like flooding or viruses infecting plants, animals or people] carrying a problematic issue, designated as $O P I$, which arises in a 'problematic situation' described by a 'story' and carrying 'properties' called 'requirements',

III. The 'product' can do this by being manufactured, assembled and/or delivered by a 'producer' to a 'notional' or 'actual' market according to 'specifications' which should satisfy the 'requirements' of an OPI and other objects involved,

IV. The 'producer' operates according to a plan as directed by a 'brain/mind',

V. The 'brain/mind' directs the 'producer' so as to result in a 'product' that can change the state of 'OPI' to lead to satisfaction of expectations of another object referred to as 'User/consumer'.

We are dealing with problem solving operating as a 'purposive system' the structure of which is shown in Figure 2.

For example, the story: 'People in a village would like to cross the river more easily than at present' in which the 'uncrossed river' caries the IS [initial state] of 'OPI', the 'not yet existing means of crossing' is the 'product' to be produced by 'producers' and the 'people' are the 'User/consumer' to be satisfied. The 'requirements' of OPI and User/utiliser should be met by 'specification' of the 'product' at a real or notional market and the 'expectations' or 'need' of people should be satisfied by the 'river crossed [FS [final state] of OPI]' to be accomplished by the product.

\section{Remarks concerning Figure 2.}

1. The diagram in Figure 2. is suggested to act as a problem-solving structure. It can help in resolving 'problematic issues' in 'straightforward' as well as in 'wicked problems' by providing a method of 'thinking' [Rittel, Webber, 1973].

2. Requirements expressed in terms of 'physical and/or mental properties' are generated by:

OPI and others like stakeholders, User/consumer and environmental features [physical like road surface or living like people's wishes and interests]. They are matched to specifications also expressed in terms of 'properties', for products and producers at a notional or real MARKET.

3. The scheme in Figure 2. includes four kinds of 'systems' or structures as particular cases [Korn, 2020a,b]:

A. Utilising systems which are recognised by their use of 'existing products'.

B. Producing systems which are recognised by their activity such as manufacturing, assembling and delivering 'products' to 'market'.

C. Trouble shooting systems existing through perception of a 'OPI, 5-6' through 'symptoms' manifested by a breakdown [of a car] caused by lack of fuel, anaemia [of a child] caused by deficiency of iron, difficult to climb [up stairs] caused by weak heart and seeking product, $\mathbf{3}$, producers, 2 to 'restore fuel supply', 'supply of iron' etc. to eliminate cause so as to satisfy a 'User/consumer, 7-8'. 


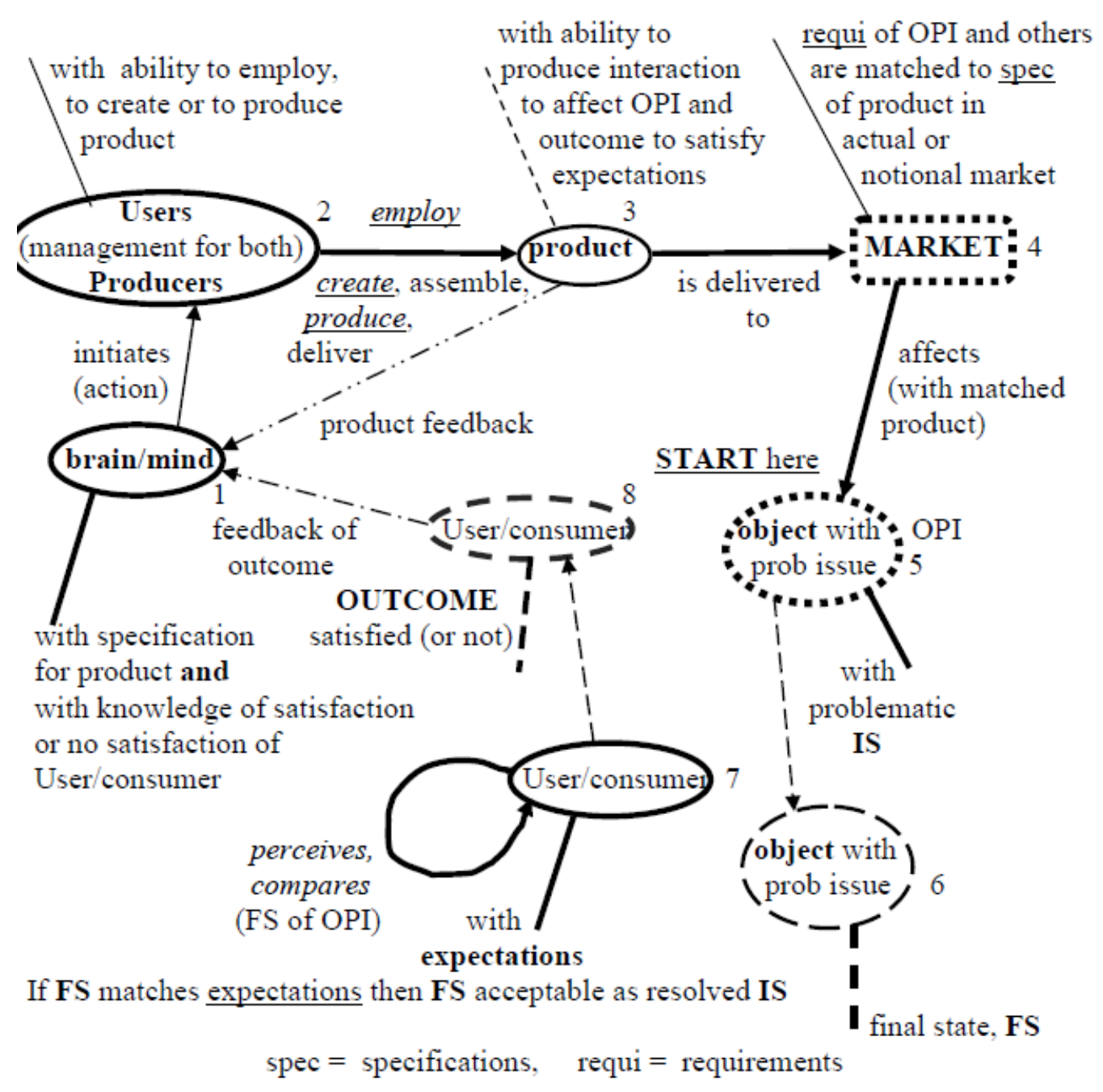

Figure 2. Diagram of problem structuring scheme.

4 D. Inanimate systems which are recognised by the presence of 'producers, 2' (with no management) producing 'product, 3' and possibly affecting a 'User/consumer, 7-8' such as a volcano producing 'lava' and 'fumes' can affect people living nearby [Korn, 2020a]. No brain/mind,1.

A 'story' or 'narrative' in natural language is expressed in terms of 'story language' which is the first step in 'linguistic modelling' to be transformed into 'homogeneous language' of ' 1 - and 2 - place sentences' by 'meaning preserving linguistic transformations'. This is the way to express the scheme in Figure 2. in 'operational terms' by 'linguistic modelling' [Korn, 2009, 2016, 2018].

5. The operation of the scheme in Figure 2. begins with perception of an object [OPI] with a 'problematic issue' which is its initial state IS emerging from the description or 'story' of a 'problematic situation' and formalised into a 'set of consistent statements with properties'. A consistent final state FS of OPI is proposed to see if it satisfies the User/consumer identified from the 'story'. Based on requirements matched to specifications at a MARKET a 'product' and 'producer' together called the 'prototype', is found by 'linguistic modelling'. For each item or 'property' a prototype system which is thought to be capable of accomplishment of the transformation from IS to FS is obtained leading to an 'overall product' [Korn, 2018]. One property can be produced at a time because only two properties can be compared, the controlled and desired, at brain/mind, 1 in Figure 2 . 


\section{STORY OF A SCENARIO}

An example is given to demonstrate the application of the scheme in Figure 2. and worked out in detail by 'linguistic modelling.

The story is devised as a scenario is interpreted by 'observer I' : 'Feeling hungry, the hawk with sharp eyes watched the surroundings for possible food. He noted the activities of iguanas not far away. Having noticed the hawk, one of the iguanas started to run which was his fatal mistake because his action immediately attracted the attention of the hawk. The hawk caught the iguana with his sharp claws so that he could not escape'.

The story consists of factual details derived from observation of the scenario with added feasible conjectures as required by the rules of linguistic modelling. The structure of the resulting linguistic model conforms to that of the general 'problem solving scheme' in Figure 2. [Korn, 2020a,b].

\section{Development of linguistic model of the story constructed by 'observer I'}

\section{A. Homogeneous language of context free, 1 - and 2 - place sentences}

These sentences define the structure or the topology or the algorithms of the scenario. They are obtained from linguistic analysis of linguistic complexities, if any, in the story by meaning preserving transformations and used for constructing semantic diagrams [Korn, Huss, Cumbers, 1991, Korn, 2009].

1. Hawk watched [the surrounding] [1-place sentence]

2. Hawk noted [the activities] [1 - place sentence]

3. Iguana started [to run....] [1 - place sentence]

4. Iguana attracted hawk [2 - place sentence]

5 . Hawk caught iguana [2 - place sentence]

\section{B. Semantic diagram}

This is shown in Figure 3. as the structure defined by the 'objects playing a part in the scenario and their interactions signified by the dynamic verbs in A. 'Functional and identifying qualifiers' are obtained from the story and added as demanded by the rules of linguistic modelling and by the subjective judgement of observer I. Adjectival qualifiers can be assigned numerical measures of 'uncertainty' of how likely an object is to have a particular property as the logic sequences evolve [Durkin, 1994, Korn, 2009]. Uncertainties of adverbial qualifiers are derived. Mathematical models can be added at object level to aid decision making.

\section{Adjectival qualifiers with grading and certainty factors (cf)}

'Grading' and 'personality profiles' can be assigned to qualifiers which, thus, vary and their effect on the performance of the object which they qualify, changes. Subjectively assessed certainty factors (cf) can be added to each grade to introduce numerical measures into the emergence of states as the scenario evolves. The technique is explained in detail in [Durkin, 1994, Korn, 2009]. 
Adjectival qualifiers with grading using cf's which are the functional and identifying qualifiers, are

$\mathrm{dp}(1,1)$ - hawk due to feeling hungry [just, .5 , very, .8]

ep $(1,1)$ - hawk sharp eyed [very, 1]

$\operatorname{ip}(1,1)-$

$\operatorname{ep}(1,3)-$

$\operatorname{ip}(1,3)$ -

$\operatorname{ep}(1,4)$ -

in $(1,4)$ -

$\operatorname{ep}(1,7)-$

$\operatorname{ip}(1,7)$ -

$\mathrm{dp}(5,5)$ - iguana having noticed

$\operatorname{ep}(5,5)-$

ip $(5,5)-$

$\mathrm{ep}(5,6 / 4)-$

$\operatorname{ip}(5,6 / 4)-$

ep $(5,6 / 7)$ -

ip(-----) - this 'interaction property' does not exist because object 6 generates no more interaction

$\mathrm{dp}(9,9)$ - observer II is prompted by the scenario as the 'hawk', no longer hungry?

$\operatorname{ep}(9,9)-$

ip $(9,9)-$

$\mathrm{ep}(9,10)-$

$\operatorname{ip}(9,10)-$ 

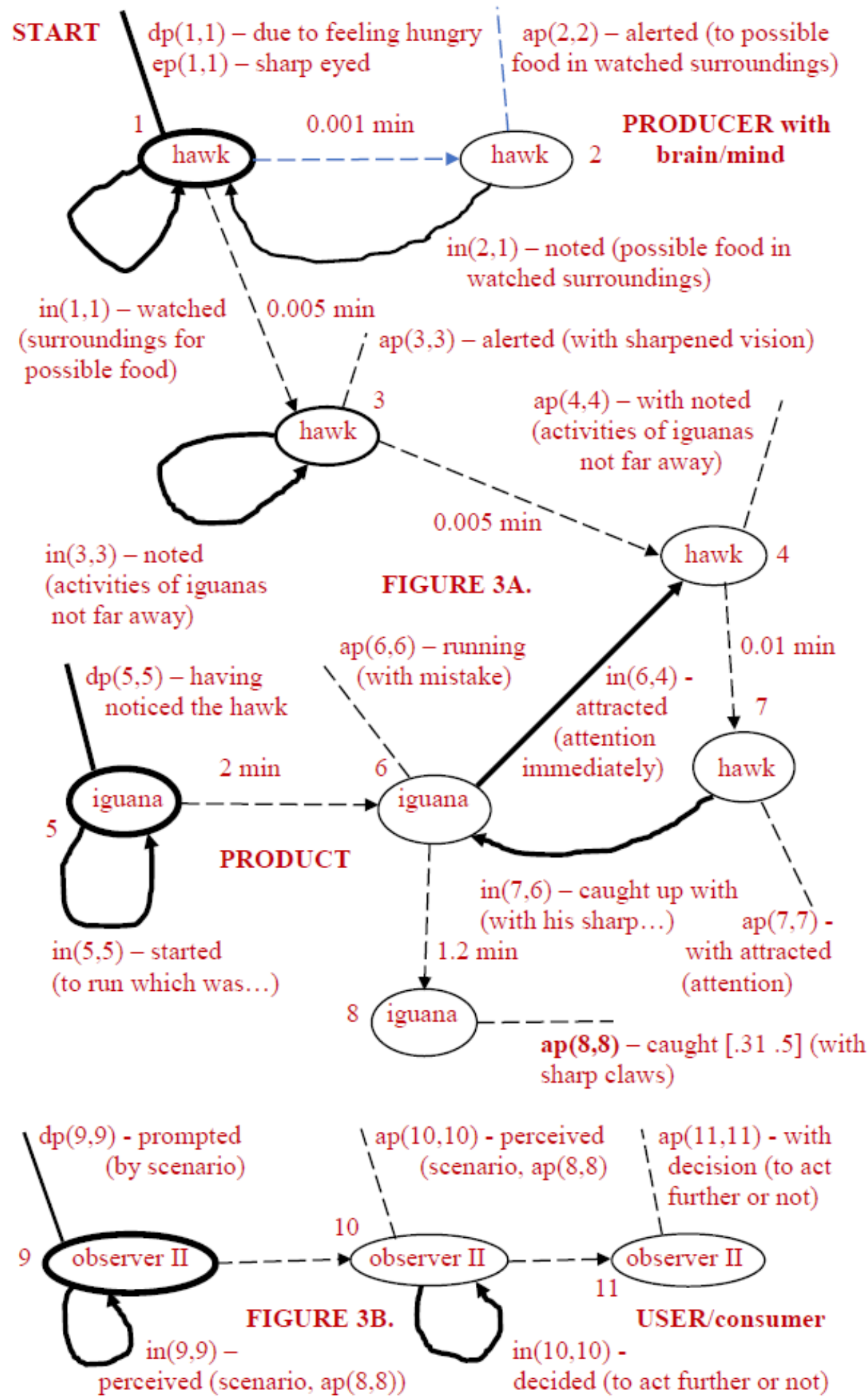

Figure 3. Hawk - iguana scenario.

We note that most of the qualifiers have no particular cases from the story or not given by observer I. There is no 'calculating properties' ' $c p(. .$.$) ', introduced to represent outside interference [Korn, 2009].$ D. Interactions with adverbial qualifiers in brackets 
in $(1,1)$-hawk watched (surroundings for possible food)

in $(2,1)$ - hawk is alerted by hawk (to possible food in watched surroundings)

in $(3,3)$ - hawk noted (activities of iguanas not far away)

in $(7,6)$ - hawk caught the iguana (with his sharp...)

in $(5,5)$ - iguana started (to run which...)

in $(6,4)$ - iguana attracted of hawk (attention immediately)

in $(9,9)$ - observer II perceived (the scenario, ap $(8,8)$ )

in $(10,10)$ - observer II decided (to act further or not)

E. Logic sequences/topology of scenario with graded qualifiers and certainty factors

The causal chains from Figure 3A.,B. : First = 7, 4, 3, 1 Second = 2, 1 Third = 8, 6, 5

Fourth $=11,10,9$

For the First and Second causal chains

$1 / 1 \mathrm{dp}(1,1)[$ just,.5, very,.8] $\rightarrow .7 \mathrm{in}(1,1)[.35, .56] \quad$ where .7 is the cf of rule

$\mathrm{cf}=.7 \times .5, .7 \times .8=.35, .56$

$1 / 2 \operatorname{in}(1,1)[.35, .56] \wedge \mathrm{ep}(1,1)[$ very, 1$] \rightarrow .9 \operatorname{ap}(\mathbf{2 , 2})[.31, .5] \quad$ these cf values are

$\mathrm{cf}=.9(\min (.35 \times 1), \min (.56 \times 1))=.31, .5 \quad$ transmitted with no

$2 / 1$ ap $(2,2) \rightarrow \operatorname{in}(2,1)$

further change

$1 / 3$ in $(2,1) \rightarrow$ ap $(3,3)$

$1 / 4$ ap $(3,3) \rightarrow \operatorname{in}(3,3)$

$1 / 5$ in $(3,3) \rightarrow \operatorname{ap}(4,4)$

to progress in the First causal chain, we need to generate in $(6,4)$ from the Third causal chain

For the Third causal chain

$3 / 1 \mathrm{dp}(5,5) \rightarrow \operatorname{in}(5,5)$

$3 / 2$ in $(5,5) \rightarrow$ ap $(6,6)$

back to First causal chain

$1 / 6$ ap $(6,6) \rightarrow \operatorname{in}(6,4)$

$1 / 7 \operatorname{in}(6,4) \wedge \operatorname{ap}(4,4) \rightarrow \operatorname{ap}(7,7)$

back to Third causal chain

$3 / 3$ ap $(7,7) \rightarrow \operatorname{in}(7,6)$

$3 / 4 \operatorname{in}(7,6) \rightarrow \operatorname{ap}(\mathbf{8 , 8})[.31 .5]$

which says that the certainty of hawk catching the iguana is less than 'may be' and 'probably' using the verbal equivalents of cf in Figure 4.3. in [Korn, 2009]. The ac/property is the OUTCOME of the scenario or final state of product impinging on Observer II.

For the Fourth causal chain

$4 / 1 \mathrm{dp}(9,9) \rightarrow \operatorname{in}(9,9)$

$4 / 2$ in $(9,9) \rightarrow$ ap $(\mathbf{1 0 , 1 0})$

$4 / 3$ ap $(10,10) \rightarrow$ in 10,10$)$

$4 / 5$ in $(10,10) \rightarrow \operatorname{ap}(\mathbf{1 1}, 11)$

the OUTCOME of Observer II which is the 'hawk', his hunger has been alleviated. 


\section{A quantitative aspect of the scenario}

A problem leading to a mathematical model of conventional science can be formulated to show how this science fits into the framework of activity by living agents.

We assume that the running speed of the iguana is $8 \mathrm{~km} / \mathrm{h}$ and he is $0.4 \mathrm{~km}$ away from his cave when he noticed the hawk i.e. danger and started to run. It would take him approximately $0.05 \mathrm{~h}$ or $3 \mathrm{~min}$ from this position to reach the cave using the formula: 'speed $=$ distance over time'. The attack speed of the hawk is $50 \mathrm{~km} / \mathrm{h}$ and he is from the iguana $1 \mathrm{~km}$ away on the outside of the $0.4 \mathrm{~km}$ away from the cave. Using the same formula the hawk can reach the iguana in $1.2 \mathrm{~min}$ and catch him.

\section{REMARKS}

Figure 3. shows a 'problem solving structure' which is a particular case of the general 'problem solving scheme' in Figure 2. depicting the progression of mental as well as physical states in time carrying information flow and skilled power [Korn, 2009, 2020a,b]. The figure depicts living agents which as such operate according to their innate 'purpose' directed at solving their own problems with the 'hawk' playing a number of functions in Figure 2.

We note that 'observer I' creates the 'linguistic model' of a cybernetic structure [Wiener, 1948]. 'Observer II', the 'hawk' in this case, usually the human or living operator, the User/consumer with expectation, observes the model, especially the 'outcome' and can be influenced by what $\mathrm{h} / \mathrm{she}$ deduces.

Mathematical modelling and aspects of 'conventional science of physics' enter the structural or relational models at 'object' level by using the symbolisms expressed in terms of qualitative and/or quantitative properties as shown in Table 1. [Korn, 2018]. In the present example, certainties of adjectival qualifiers enter the picture in quantitative terms. We note that there is uncertainty about the occurrence of 'outcome' i.e. 'hawk catches the iguana' at the 'acquire property' ap $(8,8)$ ' arising from the uncertainty at 'feeling hungry' adjectival property of the hawk.

Linguistic modelling can be used for generating both, 'functional and identifying properties' until operational level for reproducing a particular model is reached so as to test the 'outcome' against that of the model in response to a stimulus generated by a $\mathrm{dp}(----)$ property. Thus, performing at least a thought experiment.

\section{ARISTOTLE'S FOUR CAUSES SEEN AS PROBLEM SOLVING SCHEME}

According to Aristotle for the complete description of a thing or being we need four causes which may be interpreted as:

1. The material cause of a being stands for the physical properties of the material of which it is made of,

2. The formal cause of a being is its structure or design of the material [inanimate, animate, artificial],

3. The efficient cause of a being is the thing or agent which actually brings it about,

4. The final cause of a being is its ultimate purpose.

These causes usually had been discussed separately during the history of philosophy. For example, Thomas Aquinas (1225-1274) used the final cause to argue for the existence of God. An other issue is the ambiguity of the term 'purpose' which can mean 'function of an object' or a 'desired goal' [Nagel, 1968]. The 'final cause' refers to the latter. Eventually the emergence of conventional science in the Renaissance rejected the formal and final causes as incompatible with the objective view advocated.

We intend to discuss how the four causes fit into the scheme of problem-solving scheme in Figure 2. Thus, the four causes are exhibited as an integrated whole perhaps in conformity with Aristotle's idea. Accordingly, 
Final cause

Material and Formal causes

Efficient cause is seen as Expectations of a User/consumer, the goal of

the whole enterprise

، ، Product, artefact

“ “ Production/Management

OPI, the carrier of the 'problematic issue', the inspiration for the initiator of the intellectual activity of problem solving or design, is missing from the four causes together with the means of interactions to form an 'organic whole'.

The four causes fit into the problem-solving scheme only partly but there is a significant correlation which makes them to be regarded as the forerunner of this idea. The formal and final causes are important parts of problem solving which is the central point of the ' $21^{\text {st }}$ century science'.

\section{CONCLUSIONS}

The systemic or structural view of parts of the world has been put into practice by instinct due to the 'innateness' of problem solving ever since living things have existed. All human intellectual endeavour as indicated in Figure 1. together with technological achievements since ancient times have been achieved by the drive for change by inventions in the interest of survival, more convenience, higher performance, striving for power and influence, construction of monuments to demonstrate greatness and so on. All this concerns problem solving and has been aided by knowledge available at the times such as conventional science none of which is directly aimed at development of a method for problem solving.

People has been adopting to cope with this anomaly, especially today with the wide availability of computers which masks the lack of fundamental knowledge. However, in the $20^{\text {th }}$ century new approaches had been developed aimed at topics of direct concern with problem solving and of interest to living things such as information and control theories and more general ideas concerning the notion of 'systems' [Brillouin, 1956, Shannon, 1964, Korn, 2010]. However, information theory has not managed to incorporate 'meaning', control theory is signal based and design thinking and ideas concerning 'systems' is fragmented and speculative, though interesting and stipulating. So far it has not come up with an empirical, comprehensive theory to cope with the generality of the 'systemic or structural view' of parts of the world.

Aristotle's four causes have been considered because it connects ideas of conventional science with those of problem solving and points to further developments which the 'New science of systems' is intended to accomplish subject to peer review [Korn, 2018, 2019, 2020a,b]. This view shows the foresight of Aristotle and supports the need for development of this 'New science'.

The New Science of Systems has been developed in response to supplement activity by instinct driven by 'innateness' and to offer a novel approach against the deficiencies of current approaches and can offer:

1. It follows the method of conventional science of physics but with systemic content so it satisfies the criteria of being 'scientific' inclusive of a general problem solving method [Korn, $2020 \mathrm{a}, \mathrm{b}]$. It is rooted in accepted branches of knowledge, uses the symbolism of processed natural language as well as mathematics.

2. Linguistic modelling can show outcomes of scenarios with conditions of occurrence explicitly viewed as qualified objects or agents related by qualified interactions and exposed to 'acceptability criteria' by a User/consumer when formulated. This can lead to evaluation of their impact as a consequence of carrying out policies or ideas on objects in an environment.

3. Linguistic modelling can be used for planning the structure of components envisaged to be necessary for the realisation of future events such as holidays, construction of buildings or military operations and can aid their selection for carrying out particular functions. 
4. A linguistic model can accommodate aspects of conventional science creating a scientific enterprise, numerical measures of properties at object level, can be subjected to stimulus. Properties or parameters and components can be varied until acceptability of outcomes is achieved which is a design activity.

5. It accommodates the mental activity of problem solving which concerns the change of an initial state of an object with a problematic issue into resolution or final state so as to ensure that the latter fits the expectation of a User/consumer. The expectation is regarded as the goal or end to be pursued.

Design is the mental activity which concerns the creation of a functional product such as to be capable of performing the change of state and that of the production system with the function of producing the product. Here their linguistic model is called the prototype. If this model is operational then it predicts that its realisation will resolve the perceived problematic issue.

Conventional science is concerned with the generation of hypothetical statements of phenomena by inductive generalisations or principles leading to the production of mathematical models capable of testing their truth value. If true, the model can be used for prediction of events. Both systems theory and conventional science are abstractions of everyday activities or empirical phenomena.

The pervasiveness of problem-solving activity in the world viewed as systemic has been emphasised. However, current intellectual endeavours do not appreciably refer to problem solving and design in a general way, the thinking is fragmented. This paper has introduced a new approach intended to eliminate this anomaly which can encourage research for functional entities in organisations at micro and macroscopic levels. Disciplines like chemistry and nuclear physics may put more emphasis on searching for interactions as well as particles. Linguistics may be introduced into teaching as a symbolism as well as mathematics. However, applications to more realistic problems and software are needed for working out the dynamics of scenarios.

In particular, the New science can give executives and experts in specialist fields including those in the current pandemic, a generally applicable method of problem solving as a guide for thinking providing it passes peer scrutiny. This kind of method can facilitate and foster resilience and diversity of responses to undesirable events.

However, it is ideas that matter, systems or structures can only execute ideas or policies, the ideas and execution are connected by 'amplification', perhaps the most profound invention by living nature and man. The desire by the human mind for survival and for achieving ambitions like easier life, convenience, higher performance, power, nations emulating each other, has been driving inventions or vice versa, of more and more complex devices manufactured by more and more complex systems. The whole process is governed by chance which has been the way of progress of human societies. Perhaps it is time now to change over to govern humanity in accordance with purpose.

\section{RÉFÉRENCES}

ANON (1983). The Finniston Report, Engineering our future, HMSO, London, UK.

BERTALANFFY, L. (von) (1950). An outline of general systems theory, The British J for the Philosophy of Science, v1, n2, pp.134-165.

BLAKETT, P. M. S. (1948). Operational research, Advanced Science, v5, n17.

BOULDING, K. E. (1956). General systems theory, the skeleton of science, Management Science, v2, n3.

BRILLOUIN, L. (1956). Science and information theory, Academic Press, NY.

BROWN, G., CAMPBELL, D. P. (1948). Principles of servomechanism, Wiley, NY.

BURTON, S. H. (1984). Mastering English grammar, Macmillan, London, UK.

DURKIN, J. (1994). Expert systems, Macmillan, NY, USA.

JACKSON, M. C. (2000). Systems approaches to management, Plenum Pub., NY.

KORN, J. (1981). Alternative derivation of equations of motion, J of the Franklin Institute, v311, n3. 
KORN, J., HUSS, F., CUMBERS, J. (1991). Analysis and design of socio-economic systems, in 'Systems thinking in Europe', ed M. C. Jackson et al, Plenum Press, NY.

KORN, J. (2009). Science and design of systems, Troubadour Pub., Leicester, UK.

KORN, J. (2010). Concept and design of information and IS, UKAIS Conference, Oxford, March.

KORN, J. (2012). Network modelling of engineering systems, Troubadour Pub., Leicester, UK.

KORN, J. (2016). The purpose of change is problem solving, Troubadour Pub., Leicester, UK.

KORN, J. (2018). General principles of systems, Kybernetes, v47, n8.

KORN, J. (2019). Crisis in systems thinking, Kybernetes, v49, n7.

KORN, J. (2020a). Application of linguistic modelling to systems and product design, I J of Markets and Business Systems, v4, n1.

KORN, J. (2020b). Structure and resolution of systemic problems, J of Sociology and Anthropology, $\mathrm{v} 8, \mathrm{n} 3$.

KORN, J. (2020c). Developments in the resolution of systemic problems, I J of Markets and Business Systems, to be published.

KUHN, Th. (1996). The structure of scientific revolutions, U of Chicago, Pa., USA.

LEWIN, D. (1981). Engineering philosophy-the $3^{\text {rd }}$ culture, Proc of the Royal Soc of Arts, v129, n5, 653-666.

MAXWELL, J. C. (1868). On governors, Proc of the Royal Society, v16, 270-283.

MONO, J. (1972). Chance and necessity, Fontana Press.

NAGEL, E. (1968). The structure of science, Routledge \& Keegan Paul, London, UK.

NISE, N. S. (2008). Control systems engineering, Wiley, Chichester, UK.

POPPER, K. (1972). The logic of scientific discovery, Hutchinson, London.

PRIGOGINE, I. (1995). Introduction to thermodynamics of irreversible processes, $\mathrm{Ch} \mathrm{C}$ Thomas, Illiois, USA.

RITTEL, H. W., WEBBER, M. M. (1973). Dilemmas in a general theory of planning, Policy Sciences, v4, 155-169.

ROGERS, G. F. S., MAYHEW, Y. (1963). Engineering thermodynamics, Longmans, UK.

SHANNON, C. E. (1964). The mathematical theory of communication, U of Illinois Press.

SIMON, H. A. (1966). The science of the artificial, MIT Press, USA.

WIENER, N. (1948). Cybernetics or control and communication in the animal and in the machine, MIT Press, USA. 